\title{
TENDENCIES OF NOISE LEVELS IN CABS OF AGRICULTURAL TRACTORS
}

Ričardas BUTKUS, Institute of Agricultural Engineering and Safety, Faculty of Agricultural Engineering, Aleksandras Stulginskis University, Studentu g. 15b, LT-53362 Akademija, Kauno raj., Lithuania, ricardas.butkus@asu.lt

Minvydas LIEGUS, Institute of Agricultural Engineering and Safety, Faculty of Agricultural Engineering, Aleksandras Stulginskis University, Studentu g. 15b, LT-3362 Akademija, Kauno raj., Lithuania, minvydas.liegus@asu.lt

Gediminas VASILIAUSKAS, Institute of Agricultural Engineering and Safety, Faculty of Agricultural Engineering, Aleksandras Stulginskis University, Address: Studentu g. 15b, LT-53362 Akademija, Kauno raj., Lithuania, gvasiliauskas@ gmail.com (corresponding author)

\begin{abstract}
Acoustic noise is one of the most prevailing risk factors on the operators of construction, mining and agricultural machinery. Statistical data collected by State Labor inspectorate of Lithuania as well as in many other EU countries show that noise induced hearing loss (NIHL) is one of the common occupational diseases. These cases are linked to agricultural workers where noise related problems are primary. Therefore, this study includes noise level analysis in most common agricultural activities where self-propelled machinery is used. As more than 50 percent of all agricultural self-propelled machinery, namely tractors, under use in Lithuania are older than 20 years the purpose was to investigate acoustic climate in cabs. This study is based on the field data, collected from 50 agricultural tractors, manufactured since 1981. Results show that the noise lower exposure action value $L_{E X, 8 h}$ of $80 \mathrm{~dB}(\mathrm{~A})$ is expected to be exceeded for the tractors manufactured before 1991 and mostly depends on construction of tractor cab but not on working hours. Data obtained in this study can be used for preliminary noise risk assessment of tractor operators.
\end{abstract}

Keywords: noise exposure, noise level, tractor noise.

\section{INTRODUCTION}

It has been recognized over time that noise, whole-body (WBV) and hand-arm vibration (HAV) are the major causes of discomfort for the drivers of various self-propelled machines and operators of hand-held equipment. Agricultural sector is one of those, where noise problems are of common interest, yet together with increasing demand of agricultural products number of agricultural machinery also increases. Fortunately technical progress has reached the level when noise and vibration levels at self-propelled agricultural machinery are reduced to acceptable level by using technical solutions such as cab suspension or damping construction of driver seats as well as noise absorbing materials for the noise reduction. Unfortunately, the process of renewal of agricultural machinery is still insufficient, yet there are still many old machinery in EU and other countries which lack vibro-acoustic comfort.

Variation and tendencies of noise level $L_{p, A}$ or noise exposure value $L_{E X, 8 h}$ in self-propelled agricultural machinery, namely tractors, was investigated by various researchers. Many studies have showed that exposure values as well as noise level in the cabs of agricultural tractors might be as high as $130 \mathrm{~dB}$ depending on activity and equipment used (Mehmet and IIker, 2004). Broeste et al. (1989) investigated 31 tractor in his study and found that almost all of them exceeded the noise level of $85 \mathrm{~dB}(\mathrm{~A})$. Similar research was also carried out by Aybek et al. (2010), where they found that noise levels in the cabs of agricultural tractors during common agricultural operations might be as high as $110 \mathrm{~dB}(\mathrm{~A})$. These results are in agreement with those, obtained by Baryeh et al. (2003) where $82 \%$ of all agricultural tractor drivers recognized noise problem as a main hazard on their health. This study also revealed the fact, that personal protective equipment used by operators reduced their ability to hear emergency and other signals and was one of the main factors why operators avoid wearing headphones.

Extended research of noise in tractor cabs was done by Holt et al. (2006) where noise levels of 155 tractors on 36 farms were studied. The range of noise levels at the driver's ear position with radios off and windows closed varied from 78 to $103 \mathrm{~dB}(\mathrm{~A})$. Three quarters of tractors without cabs had noise levels in excess of $90 \mathrm{~dB}(\mathrm{~A})$, compared to $18 \%$ of tractors equipped with cabs. These authors also identified significant add on noise level from radio (average of $3.1 \mathrm{~dB}$ ) and from open windows (average of $4.2 \mathrm{~dB}$ ). From the results of this study, authors recommend hearing protection when working time on a tractor with a cab approaches 3 to 4 hours and when time on a tractor without a cab approaches 1.5 to

Copyright (C) 2015 The Authors. Published by Aleksandras Stulginskis University. This is an open-access article distributed under the terms of the Creative Commons Attribution License (CC-BY 4.0), which permits unrestricted use, distribution, and reproduction in any medium, provided the original author and source are credited. 
2 hours. These results are well correlated to the findings made by Commonwealth of Australia in 2010 where was stated, that $50 \%$ of agriculture, forestry and fishery sectors' workers are irritated by noise while $36 \%$ feel tiredness because of noise influence. Same study also states that only $72 \%$ of all agricultural workers have and wear hearing protectors (Occupational noise-induced..., 2010).

Above presented results clearly correlates to medical studies, where noise induced hearing loss (NIHL) was investigated. Many studies have shown that long exposures to high noise or vibration levels can have adverse effects on human health while agriculture shows largest number of hearing loss amongst other occupations (Baker, 1993). Solecki (2003) investigated occupational hearing loss amongst farmers and found, that 30 year exposure to daily noise levels might produce the hearing threshold shift by $5.5 \mathrm{~dB}$ and $14.5 \mathrm{~dB}$ together with age related hearing loss. NIHL is also one of the common occupational diseases registered in Lithuania (approx. 100 cases yearly).

These examples clearly show the necessity to pay special attention to noise problems in agriculture as well as in other sectors and to reduce negative effects on workers. The solution of these problems is usually implemented by reconstructing a particular workplace, shortening work shift duration, using personal hearing protection or applying technical noise reduction means. In 2004 British Health and Safety Executive (HSE) released a document for practical solutions to noise problems in agriculture, where discussed the relevancy of agricultural sector from the perspective of various agricultural activities, such as mobile and stationary machinery, husbandry and offered some case studies for possible noise reduction ways (Evans et al., 2004). Similar document with practical implementation was also published by Butkus et al. (2005) in Lithuania with a special focus on noise risk assessment and methodology.

However, the use of technical solutions in used agricultural machinery or tractors usually meet practical and economical implementation problems. In the study of Evans (Evans et al., 2004) it was shown that noise absorbing materials could significantly decrease noise levels in tractor cabs which could be in the range $3-16 \mathrm{~dB}(\mathrm{~A})$ at operator ear level. Such reduction could also decrease the 8 hour noise exposure action value $L_{E X, 8 h}$ up to $16 \mathrm{~dB}(\mathrm{~A})$, but there is little to deter of such solutions other than price and labor expenditures.

It should be noted that above mentioned problems usually arise from machinery, which was produced few decades ago and does not apply to modern machinery. According to the data provided by the state enterprise Agricultural Information and Rural Business Centre, 1 June 2015, there were approx. 150000 wheeled tractors in Lithuania. Majority of them (>50 percent) are older than 20 years and lack of vibro-acoustic safety.

The manufacturer of any machinery should give information concerning the noise it produces. Desirous to minimize negative impact of noise on operator, noise exposure limit action value of $87 \mathrm{~dB}(\mathrm{~A})$ was specified in EU directive 2003/10/EC, while EU Directive 2009/76/EC (Annex II) establishes that the maximum permissible noise level at the operator's ear position inside tractor cab is $86 \mathrm{~dB}(\mathrm{~A})$. Modern machinery meets the requirements and offers even better acoustic comfort to operators, yet noise levels can be as low as $70 \mathrm{~dB}(\mathrm{~A})$ in modern cabs.

The research goal was to determine the relationship between noise level and manufacturing year of agricultural tractors used in Lithuania.

\section{METHODOLOGY}

Noise exposure levels and its effects on workers' health are limited by legislation such as the EU directive 2003/10/EC "On the minimum health and safety requirements regarding the exposure of workers to the risks arising from physical agents (noise)". The requirements of this directive are transferred to the laws of EU member states and obligate the employers to assess the occupational risk and to foresee the possibilities to reduce noise risk on workers. However, the exposure to noise can have a number of physiological and psychological effects, therefore in situ analysis is usually required.

The EU Directive 2003/10/EC regulates the minimum health and safety requirements to workers arising from noise exposure. Limit values and exposure action values in respect of the daily noise exposure levels $\left(L_{E X, 8 h}\right)$ and peak sound pressures $\left(p_{\text {peak }}\right)$ are fixed at:

a) peak sound pressure $\left(p_{\text {peak }}\right)$ : maximum value of the $\mathrm{C}$-weighted instantaneous noise pressure;

b) daily noise exposure level $\left(L_{E X, 8 h}\right)$ for a nominal eight-hour working day as defined by ISO 1999:2004;

c) weekly noise exposure level as a time-weighted average of the daily noise exposure levels for a five working days as defined by ISO 1999:2004.

The exposure limit values and exposure action values in respect of the daily noise exposure levels and peak sound pressure $\left(L_{C, p e a k}\right)$ are fixed at:

- Exposure limit values: $L_{E X, 8 h}=87 \mathrm{~dB}(\mathrm{~A}), p_{\text {peak }}=200 \mathrm{~Pa}, L_{C, p e a k}=140 \mathrm{~dB}(\mathrm{C})$;

- Upper exposure action values: $L_{E X, 8 h}=85 \mathrm{~dB}(\mathrm{~A}), p_{\text {peak }}=140 \mathrm{~Pa}, L_{C, p e a k}=137 \mathrm{~dB}(\mathrm{C})$;

- Lower exposure action values: $L_{E X, 8 h}=80 \mathrm{~dB}(\mathrm{~A}), p_{\text {peak }}=120 \mathrm{~Pa}, L_{C, p e a k}=135 \mathrm{~dB}(\mathrm{C})$.

If the worker (operator) is exposed to noise less than eight hours per day and the noise level changes tangibly at different time periods, the A-weighted sound pressure level can be calculated as output of working time and noise level over the time period $T_{e}$ :

$$
L_{A, e q, T e}=10 \lg \left[\frac{1}{T_{e}} \sum_{i=1}^{n} t_{i} \cdot 10^{0,1 L_{\text {Aeq }, i}}\right], \mathrm{dBA},
$$


where: $\quad L_{A e q, T e}$ - equivalent A-weighted sound pressure level over the measurement period $t_{i}$ $i$ - number of measurement intervals. Overall duration $t_{i}$ of the intervals is $T_{e}$.

Daily noise exposure of 8 hours is calculated as follows:

$$
L_{E X, 8 h}=L_{A e q, T e}+10 \lg \left(\frac{T_{e}}{T_{0}}\right), \mathrm{dBA},
$$

where: $\quad L_{A e q, T e}-$ measured A-weighted sound pressure level over particular time period $T_{e}$;

$T_{0}-$ reference duration of 8 working hours. Dimensions $T_{0}$ and $T_{e}$ have the same dimensions (hours, minutes, seconds).

The parameter $L_{E X, 8 h}$ is closely related to noise dose $D$. This means that exposure level of $85 \mathrm{~dB}(\mathrm{~A})$ gives $100 \%$ noise dose. Any level above the value of $85 \mathrm{~dB}(\mathrm{~A})$ in three decibel steps increases noise dose twice or reduces exposure duration twice.

In order to collect data in tractor cabs, acoustic measurements of overall noise level (A-weighted), noise spectrum levels $L_{p, i}$ and $L_{c, p e a k}$ levels were measured. Measurements were done according to the procedure used for occupational safety purposes, i.e. microphone of noise level meter was hold at the ear level on oriented towards tractors' front. Noise measurements were repeated three times and undertaken using a class 1 Brüel\&Kjær sound level meters type 2250 and 2270 and sound level meter DeltaOHM 2010. Total number of 50 tractors (which include MTZ, Belarus, T-150, T-25, John Deere, New Holland, Fendt, Zetor, Massey Ferguson, Claas and Deutz) was used for noise level measurements. Environmental conditions during measurements were as stated in EU Directive 77/311/EEC. Measurements were carried out at most frequent engine revolution speed of $1800 \mathrm{~min}^{-1}$.

\section{RESULTS}

The results of noise measurements show wide variability of noise levels in cabs. As this investigation involved modern and used agricultural tractors, noise levels varied from $67.7 \mathrm{~dB}(\mathrm{~A})$ to $94.7 \mathrm{~dB}(\mathrm{~A})$ and $L_{C, \text { peak }}$ from $85 \mathrm{~dB}(\mathrm{C})$ to $119 \mathrm{~dB}(\mathrm{C})$ respectively. The tendency of noise level change clearly correlates to manufacturing year, i.e. the newer the tractor, the lower the level. Some authors usually discuss the influence of working hours on noise level in cabs, which is critical but not essential factor. Main reason of low noise level in cabs is mostly influenced by technical solution for noise and vibration reduction, such as damping construction of cab, good noise insulation because of sealing quality etc. These results also indicate lack of vibro-acoustic safety in old machinery which was made in Commonwealth of Independent States (CIS). Results of noise measurements as a dependence of manufacturing year is shown in figure 1.

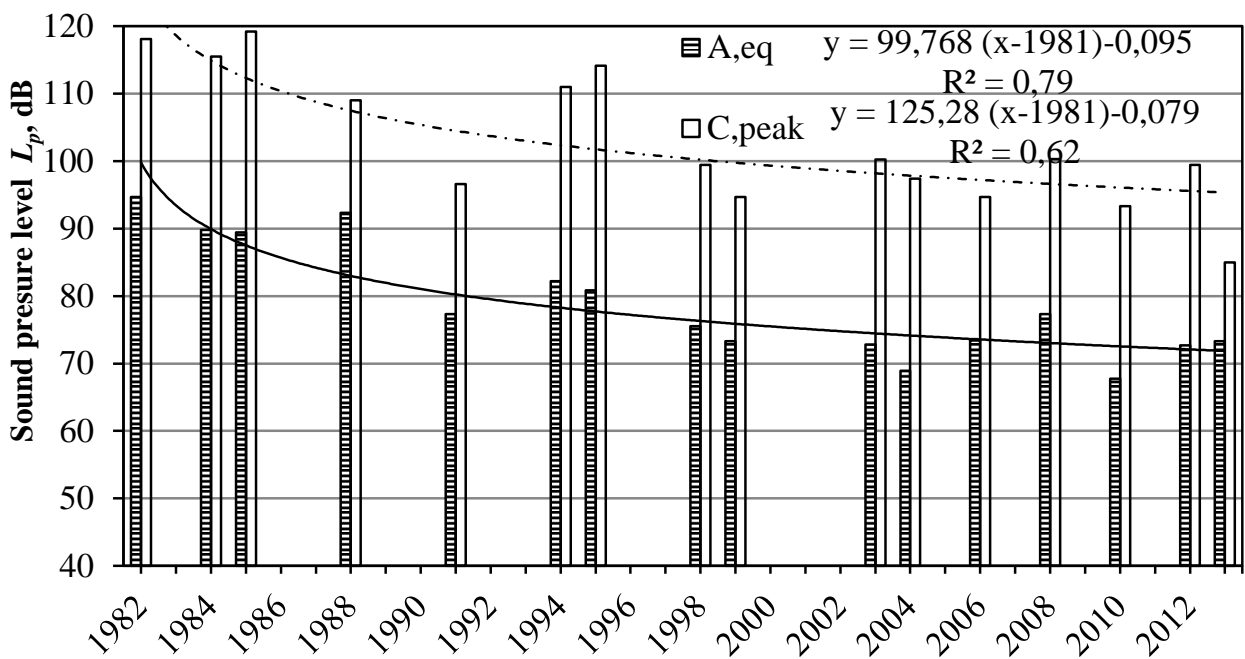

Manufacturing year

Figure 1. Sound pressure levels $L_{p, A}$ and $L_{C, p e a k}$ in the cabs of tractors

As seen in Figure 1, exposure lower value of $80 \mathrm{~dB}(\mathrm{~A})$ (when work shift duration is 8 hours) is expected not be exceeded if the tractor was manufactured later than 1991. This data might be useful in performing preliminary risk assessment of tractor drivers yet can give a guidelines for further actions. From the data presented above it can be concluded, that in Lithuania > $50 \%$ of all tractors were manufactured earlier which means that operators of such tractors should reduce work time shift or to use hearing protection. Special attention should be addressed to the workplaces, when noise level exceeds the value of $87 \mathrm{~dB}(\mathrm{~A})$ or these tractors were manufactured earlier than 1985 . Noise exposure $L_{E X, 8 h}$ calculations for these levels are given in Table 1. These results show, that for most noisy workplaces exposure lower value is exceeded in 16 minutes, while exposure limit value in less than one and half hour (Table 1). 
In order to compare spectral differences which could justify significantly higher $L(C)$ levels in cabs presented in Figure 1, all investigated tractors were divided into two groups, i.e. those made to the year 2000 and those after. Figure 2 shows spectral levels and its deviations in $1 / 1$ octave frequency bands. It can be concluded that largest differences were found at low and high frequency bands of 16 and $16000 \mathrm{~Hz}(21.3$ and $18.3 \mathrm{~dB}$ respectively) while average difference in spectral levels was $13.4 \mathrm{~dB}$. These results could be of interest from the perspective of preventative noise reduction actions such as cab insulation, structural noise reduction or others.

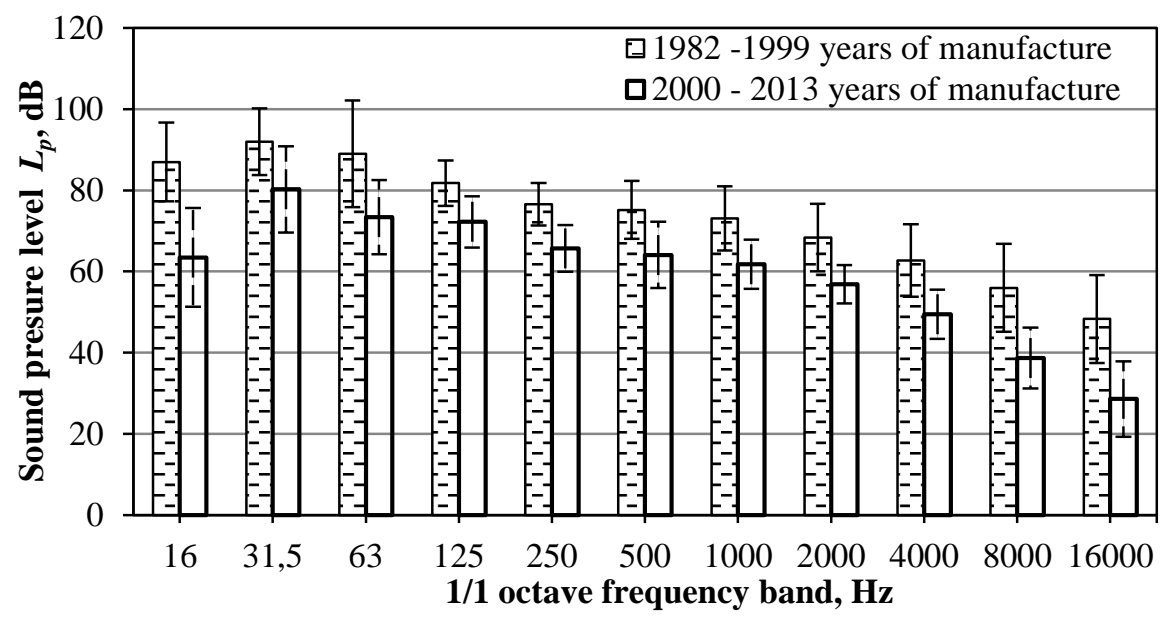

Figure 2. 1/1 octave frequency spectrums of tractor noise $L_{p, o c t}$

Table 1. Relation of measured A-weighted SPL and time to reach lower, upper and limit values exposure values

\begin{tabular}{|c|c|c|c|}
\hline \multirow{2}{*}{$\boldsymbol{L}_{\boldsymbol{p}, \boldsymbol{A}, \boldsymbol{d B}(\boldsymbol{A})}$} & \multicolumn{3}{|c|}{ Time to reach $\boldsymbol{L}_{\boldsymbol{E X}, \boldsymbol{s h}}(\boldsymbol{h h}: \boldsymbol{m m}) \boldsymbol{o f :}$} \\
\cline { 2 - 4 } & $\mathbf{8 0} \mathbf{d B}(\boldsymbol{A})$ & $\mathbf{8 5} \boldsymbol{d B}(\boldsymbol{A})$ & $\mathbf{8 7} \boldsymbol{d B}(\boldsymbol{A})$ \\
\hline 94.7 & $00: 16$ & $00: 51$ & $01: 21$ \\
\hline 92.3 & $00: 28$ & $01: 30$ & $02: 23$ \\
\hline 89.4 & $00: 55$ & $02: 55$ & $04: 35$ \\
\hline 82.2 & $04: 50$ & $>08: 00$ & $>08: 00$ \\
\hline
\end{tabular}

As seen in figure 2, there are no significant differences in spectral pattern of tractor noise of different years of manufacture. As we divided tractors to 2 groups, deviations in frequency bands are wide ranging but there is a tendency of dominant low and mid frequencies. However, there is a vast difference of $\sim 20 \mathrm{~dB}$ between modern and used CIS made tractors.

\section{CONCLUSIONS}

1. Sound pressure levels as well as exposure levels in tractor cabs at ear level were in a decreasing trend as manufacturing year increased. Average decrease of $\sim 1 \mathrm{~dB} /$ year in noise level was noticed.

2. Spectral analysis of noise level in tractor cabs show that low frequency noise $(16-125 \mathrm{~Hz})$ is dominant in tractor cabs. Spectral pattern does not depend on manufacturing year, except that noise levels of tractors, manufactured after year 2000 , in frequency bands are on average $13.4 \mathrm{~dB}$ lower which gives significant improvement on noise exposure levels.

3. Lower, upper and exposure limit values in old tractors are exceeded in durations much shorter than operators usually operate these tractors. Exposure lower value for noisiest tractors is reached in 16 minutes, while exposure limit in less than one hour and half. It can be concluded, that normal working conditions with exposure level of $80 \mathrm{~dB}(\mathrm{~A})$ are achieved the tractor was manufactured after year 2000.

\section{REFERENCES}

1. Aybek, A., Kamer, H. A., Arslan, S. 2010. Personal noise exposures of operators of agricultural tractors. Applied Ergonomics, Vol. 41, Iss. 2, pp. 274-281. http://dx.doi.org/10.1016/j.apergo.2009.07.006

2. Baker, D. E. Noise: the invisible hazard. Available at <http://extension.missouri.edu/p/g1962> (accessed on 25/05/2015).

3. Baryeh, E. A., Mazwiduma, J. P., Koloka, O. A., Ampofo E. A. 2003. Hazard Assessment of Tractor Operators Engaged in Food Production in Botswana. Food Agriculture and Environment, Vol. 1, Iss. 3-4, pp. 295-299.

4. Broeste, S. K., Hansen, D. A., Strand, R. L. Stueland, D. T. 1989. Hearing Loss among High School Farm Students. American Journal of Public Health, Vol. 79, Iss. 5, pp. 619-622. http://dx.doi.org/10.2105/AJPH.79.5.619

5. Butkus, R., Deikus, J., Merkevičius, S., Šarlauskas, A. 2005. Praktinės rekomendacijos darbuotojų apsaugos nuo triukšmo keliamos rizikos nuostatams taikyti. 70 p. Available at: 〈http://www.vdi.lt/atmuploads/triuksmokeliamosrizikosnuostatutaikymas.pdf> (accessed on 20/05/2015) (In Lithuanian). 
6. Evans, J. P., Whyte, R. T., Price, J. S., Bacon, J. M., Semple, D. A., Scarlett, A. J. Practical solutions to noise problems in agriculture 2004, HSE. Available at: <http://www.hse.gov.uk/research/rrpdf/rr212.pdf> (accessed on 25/06/2015).

7. EU Directive 2009/76/EC, Relating to the driver-perceived noise level of wheeled agricultural or forestry tractors, July 13, 2009.

8. EU Directive 2003/10/EC, On the minimum health and safety requirements regarding the exposure of workers to the risks arising from physical agents (noise), February 6, 2003.

9. EU Directive 77/311/EEC, Approximation of the Laws of the Member States Relating to the Driver-perceived Noise Level of Wheeled Agricultural or Forestry Tractors, March 29, 1977.

10. Holt, J. J., Broste, S. K., Hansen, D. A. 1993. Noise exposure in the rural setting. Laryngoscope, Vol. 103, Iss. 3, pp. $258-262$. http://dx.doi.org/10.1288/00005537-199303000-00004

11. ISO 1999:2004 Acoustics. Determination of occupational noise exposure and estimation of noise-induced hearing impairment.

12. Mehmet, R. D. Iiker, H. C. 2004. Noise Levels of Various Agricultural Machineries. Pakistan Journal of Biological Sciences, Vol. 7, Iss. 6, pp. 895-901. http://dx.doi.org/10.3923/pjbs.2004.895.901

13. Solecki, L. 2003. Preliminary evaluation of occupational hearing loss risk among private farmers. Annals of Agricultural and Environmental Medicine, Vol. 10, No. 2, pp. 211-215.

14. Australian Government Department of Health and Ageing. 2010. Occupational noise-induced hearing loss in Australia. Overcoming barriers to effective noise control and hearing loss prevention. Available at: <http://www.safeworkaustralia.gov.au/sites/swa/about/publications/

Documents/539/Occupational_Noiseinduced_Hearing_Loss_Australia_2010.pdf > (accessed on 25/05/2015). 